\title{
The Course of von Willebrand Factor and Factor VIII Activity in Patients with von Willebrand Disease during Pregnancy
}

\author{
Christiane Delbrück Wolfgang Miesbach \\ Department of Haemostaseology and Haemophilia Centre, University Hospital Frankfurt, Frankfurt am Main, Germany
}

\author{
Keywords \\ Von Willebrand disease - Von Willebrand factor . \\ Pregnancy · Factor VIII
}

\begin{abstract}
Introduction: Women with von Willebrand disease (VWD) are at a higher risk of bleeding, which might affect the health of mother and child during pregnancy and the intra- and postpartum periods. This retrospective cohort study evaluates changes in the coagulation parameters von Willebrand factor antigen (VWF:Ag), von Willebrand ristocetin cofactor (VWF:RCo), and Factor VIII activity (FVIII:C) during pregnancy in patients with VWD. In total, 44 pregnancies of 38 patients were assessed (VWD type $1 n=32$, type $2 \mathrm{~A} n=3$, type $2 \mathrm{~B} n=$ 1 , type 2 subtype unidentified $n=2$ ). The patients' median age at childbirth was 32 years (range 22-40). Results: A significant increase in coagulation parameters was found in patients with VWD type 1 (VWF:Ag, VWF:RCo, and FVIII:C $p=$ 0.000). In the third trimester, VWF:Ag and FVIII:C normalized in all patients with VWD type 1; in 3 patients VWF:RCo remained below the normal range. Patients with VWD type 2 showed a significant increase of VWF:Ag $(p=0.003)$ and FVIII:C $(p=0.011)$, and a non-significant increase of VWF:RCo
\end{abstract}

$(p=0.097)$. In 4 of 9 pregnancies of patients with VWD type 2 , all surveyed coagulation parameters normalized until the third trimester. Conclusion: For the majority of the observed patients, the von Willebrand parameters increased during pregnancy.

(c) 2019 S. Karger AG, Basel

\section{Introduction}

Von Willebrand disease (VWD) is the most common hereditary bleeding disorder. It is characterized by a tendency to enhanced and prolonged bleeding. The severity of bleeding correlates with the type of VWD (type 1,2, or 3) and therefore with the deficiency or dysfunction of von Willebrand factor (VWF). VWF is a multimeric plasma protein that mediates thrombocytic adhesion to the subendothelium as well as thrombocyte aggregation. Moreover, it is a carrier protein of Factor VIII (FVIII). VWD type 1 is characterized by a quantitative deficiency of VWF and is the most common type of VWD. Patients suffer from mild bleedings. VWD type 2 is characterized by qualitative dysfunction of VWF. Type 2 is further classified into four subtypes $(2 \mathrm{~A}, 2 \mathrm{~B}, 2 \mathrm{M}$, and $2 \mathrm{~N})$ and pres-

\section{KARGER}

(c) 2019 S. Karger AG, Basel

E-Mail karger@karger.com

www.karger.com/aha
Prof. Dr. med. Wolfgang Miesbach

Department of Haemostaseology and Haemophilia Centre

University Hospital Frankfurt, Medical Clinic 2/Institute of Transfusion Medicine

Theodor-Stern-Kai 7, DE-60590 Frankfurt am Main (Germany)

E-Mail wolfgang.miesbach@kgu.de 
Table 1. Patients' characteristics: VWD types and subtypes

\begin{tabular}{|c|c|c|c|c|c|c|}
\hline VWD & Pregnancies, $n$ & Women, $n$ & $\begin{array}{l}\text { Prepregnancy bleeding } \\
\text { history, median ISTH } \\
\text { bleeding score (min., max.) }\end{array}$ & $\begin{array}{l}\text { Age at first } \\
\text { diagnosis, years } \\
\text { (range) }\end{array}$ & $\begin{array}{l}\text { Family history } \\
\text { of bleeding, } n\end{array}$ & $\begin{array}{l}\text { Family history } \\
\text { of thrombosis, } \\
n\end{array}$ \\
\hline Type $2 \mathrm{~A}$ & 3 & 3 & $2(0,11)$ & $23(9-35)$ & 1 & 0 \\
\hline Type 2B & 2 & 1 & 0 & 7 & 1 & 0 \\
\hline Total & 44 & 38 & $2(0,11)$ & $25.5(7-38)$ & 10 & 6 \\
\hline
\end{tabular}

ents with more severe bleeding symptoms. VWD type 3 is the rarest type of VWD, in which VWF is nearly completely absent [1].

Patients with VWD suffer from mucosal, joint, and muscle bleeding and bleeding after surgery. The most common manifestations are mild mucosal bleeding and prolonged menstruation [2].

Increases of von Willebrand factor antigen (VWF:Ag), von Willebrand ristocetin cofactor (VWF:RCo) levels, and FVIII activity (FVIII:C) during pregnancy in healthy women have often been described. Physiologically, several changes in the coagulation system occur. In addition to various procoagulatory processes, fibrinolysis is activated. Whereas levels of fibrinogen, FVII, FVIII, von Willebrand parameters, FX, and PAI-1 increase, levels of protein S, FXI, and FXIII show a tendency to decrease $[3,4]$.

The insufficiency of the coagulation system during pregnancy and in the intrapartum and postpartum periods may put the health of VWD patients and their foetuses at risk. This study evaluates the change in the coagulation parameters VWF:Ag, VWF:RCo, and FVIII:C as pregnancy progresses in patients with VWD.

\section{Methods}

After approval by the Ethics Commission of the University Hospital Frankfurt am Main, Germany, data files of female patients with known VWD from the haemophilia centre of the University Frankfurt, Germany, who were pregnant in the period from 2007 to 2013, were retrospectively screened for VWF:Ag, VWF:RCo, and FVIII:C records. A VWD multimeric analysis was carried out to confirm the diagnosis. Only successful pregnancies were included. Only data for VWF:Ag, VWF:RCo, and FVIII:C levels determined under the same conditions were eligible to minimize equipment- or assay-dependent variations. Prepregnancy bleeding history was assessed by the ISTH bleeding score [5].
Table 2. Patients' characteristics: age distribution and number of blood draws

\begin{tabular}{lll}
\hline & $\begin{array}{l}\text { Age at } \\
\text { childbirth, years }\end{array}$ & $\begin{array}{l}\text { Blood draws } \\
\text { per pregnancy, } n\end{array}$ \\
\hline Median & 32 & 3 \\
Min. & 22 & 2 \\
Max. & 40 & 9 \\
\hline
\end{tabular}

All data assessed were measured by the same method, the same device, and by the same staff. The assays were performed under regular control through international interlaboratory tests. Only data free from influences such as substitution (plasma samples were drawn not earlier than 10 days after the last replacement dose) and inflammation (CRP negative, normal leucocyte count) were eligible. The statistical methods that were applied included Pearson regression and the Wilcoxon matched-pairs test.

\section{Results}

Laboratory parameters of 44 pregnancies ( 38 patients) were assessed. The patients' median age at childbirth was 32 years (range $22-40$ ). The patients' median age at first VWS diagnosis was 25.5 years (range $7-38$ ). The median number of blood draws per pregnancy (including baseline determination) was 3 (2-9 withdrawals). Baseline parameters were determined before or at least 6 months after pregnancy (Tables 1,2$)$. The patients' median ISTH bleeding score before pregnancy was $2(0-11)$. Ten patients had a positive family history of bleeding, and 6 patients had a positive family history of thrombosis.

Five patients suffered from one or two additional disorders of the coagulation system (lupus anticoagulants $n=2$, dysfibrinogenemia $n=1$, heterozygous FV Leiden mutation $n=2$, heterozygous FII mutation $n=1$, protein 
Table 3. VWF:Ag, VWF:RCo, and FVIII:C during pregnancy in patients with VWD type 1 (35 pregnancies)

\begin{tabular}{|c|c|c|c|}
\hline Regression coefficient b & VWF:Ag & VWF:RCo & FVIII:C \\
\hline Median & 2.76 & 2.02 & 2.30 \\
\hline Standard deviation & 1.48 & 1.12 & 1.38 \\
\hline$p$ (Wilcoxon matched-pairs test) & 0.000 & 0.000 & 0.000 \\
\hline $\mathrm{b}>0$ & 35 & 34 & 35 \\
\hline $\mathrm{b}<0$ & 0 & 1 & 0 \\
\hline \multicolumn{4}{|l|}{ Baseline $(n=35)$} \\
\hline Median plasma concentration, $\%$ & 56.3 & 51 & 80 \\
\hline Standard deviation & 10.3 & 9.5 & 18.7 \\
\hline Out of normal range, $n$ & 20 & 35 & 9 \\
\hline \multicolumn{4}{|l|}{ 1st trimester $(n=19)$} \\
\hline Median plasma concentration, $\%$ & 67.2 & 56.9 & 94.4 \\
\hline \multicolumn{4}{|l|}{ 2nd trimester $(n=25)$} \\
\hline Median plasma concentration, $\%$ & 104.7 & 85.9 & 128.9 \\
\hline \multicolumn{4}{|l|}{ 3rd trimester $(n=35)$} \\
\hline Median plasma concentration, $\%$ & 148.5 & 114.5 & 157 \\
\hline Standard deviation & 62.1 & 44.2 & 53.5 \\
\hline Out of normal range, $n$ & 0 & 3 & 0 \\
\hline \multicolumn{4}{|c|}{ Difference between baseline and 3rd trimester $(n=35)$} \\
\hline Median plasma concentration, $\%$ & 91.1 & 67.3 & 77.9 \\
\hline Standard deviation & 58.0 & 43.8 & 49.7 \\
\hline
\end{tabular}

S deficiency, $n=1$, FXII deficiency $n=1$, FXI deficiency $n=2)$. Thrombosis prophylaxis was performed in these patients. None of the patients received factor substitution treatment and no complications occurred.

\section{Type 1 VWD}

A significant increase of the coagulation parameters VWF:Ag, VWF:RCo, and FVIII:C was found in data collected from patients with VWD type 1 (Wilcoxon matched-pairs test, $p=0.000$; Table 3, Fig. 1). The median baseline concentration of VWF:Ag was 56.3\% (33-78.6\%, $\sigma=10.3)$, that of VWF:RCo was $51 \%(23-58.7 \%, \sigma=9.5)$, and that of FVIII:C was $80 \%(50-130 \%, \sigma=18.7)$. At least one of the baseline parameters of VWF:Ag, VWF:RCo, and FVIII:C was below the cut-off for normal in every patient outside of pregnancy (VWF:Ag and VWF:RCo $<60 \%$; FVIII:C <50\%).

The median plasma concentration in the third trimester of VWF:Ag was $148.5 \%(65.1-327.1 \%, \sigma=62.1)$, that of VWF:RCo was $114.5 \%(47.4-230.3 \%, \sigma=44.2)$, and that of FVIII:C was $157 \%(114.4-328 \%, \sigma=53.5)$. By the third trimester, coagulation parameters of patients with VWD type 1 WF:Ag and FVIII:C normalized, whereas VWF:RCo remained below the normal range in 3 patients. The median plasma concentration of VWF:Ag and FVIII:C had already reached normal parameters in the first trimester (VWF:Ag 67.2\%, 43.3-111.1\%, and FVIII:C $94.4 \%, 62.6-160 \%)$. The median difference between baseline and plasma concentrations measured in the third trimester of VWF:Ag was $91.1 \%(3.7-266.1 \%, \sigma=58.0)$, that of VWF:RCo was $67.3 \%(-2.6$ to $186.3 \%, \sigma=43.8)$, and that of FVIII:C was $77.9 \%(8.2-243 \%, \sigma=49.7)$.

\section{Type 2 VWD}

Patients with VWD type 2 showed significant increases of plasma levels of VWF:Ag $(p=0.003)$ and FVIII:C $(p=0.012)$, but not for plasma concentration of VWF:RCo ( $p=0.098)$ as assessed by the Wilcoxon matched-pairs test (Table 4, Fig. 2). The median baseline concentration of VWF:Ag was $40.5 \%(12.3-64.8 \%$; $\sigma=21.3)$, that of VWF:RCo was $20 \%(13.4-55.4 \%, \sigma=19.8)$, and that of FVIII:C was $75 \%(23.8-82.2 \%, \sigma=20.6)$. The baseline plasma concentrations of at least one determined coagulation factor were out of the normal range outside of pregnancy (VWF:Ag <60\%, VWF:RCo $<60 \%$, or FVIII:C < $50 \%)$.

The median plasma concentration in the third trimester of VWF:Ag was $91.2 \%(23-165.3 \%, \sigma=49.2)$, that of VWF:RCo was $21.6 \%(13-117.9 \%, \sigma=44.6)$, and that of FVIII:C was $98.8 \%(45-174.1 \%, \sigma=43.5)$. In 4 of 9 patients with VWD type 2 , all measured plasma concentrations of coagulation parameters normalized during preg- 
Fig. 1. VWF:Ag (green dots, blue line), VWF:RCo (purple squares, red line), and FVIII:C (green triangles, green line) during pregnancy in patients with VWD type 1.

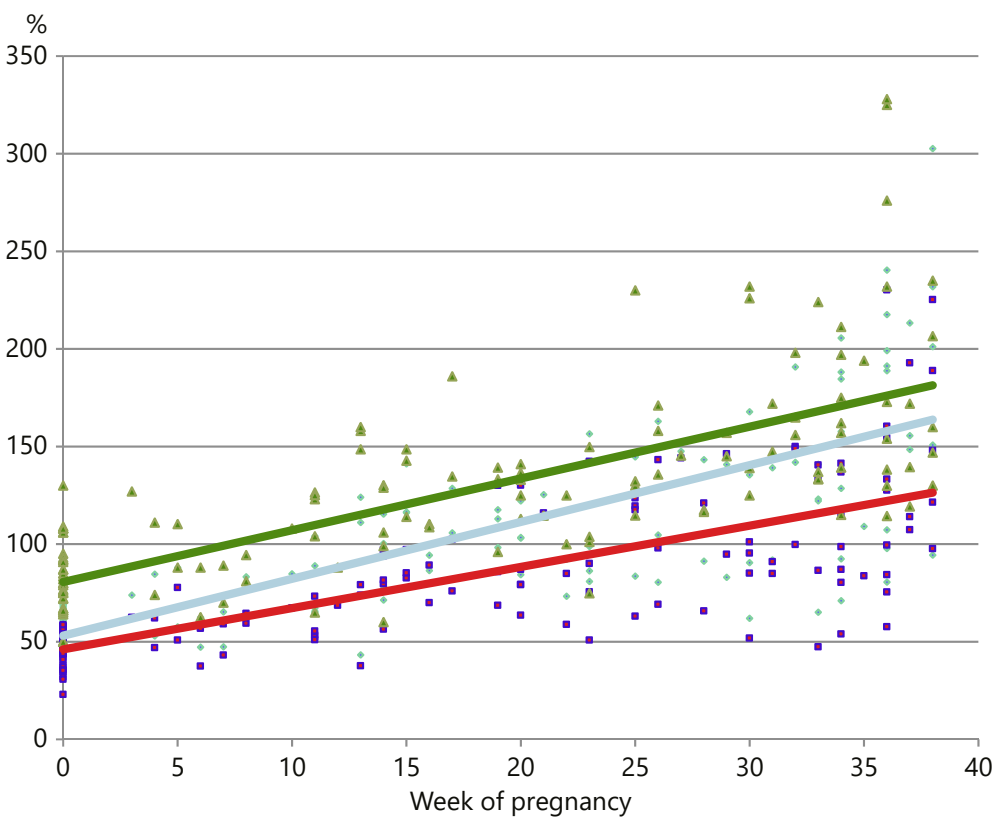

Table 4. VWF:Ag, VWF:RCo and FVIII:C during pregnancy in patients with VWD type 2 (9 pregnancies)

\begin{tabular}{|c|c|c|c|}
\hline Regression coefficient b & VWF:Ag & VWF:RCo & FVIII:C \\
\hline Median & 1.33 & 0.18 & 0.96 \\
\hline Standard deviation & 0.99 & 0.79 & 0.95 \\
\hline$p$ (Wilcoxon matched-pairs test) & 0.003 & 0.097 & 0.011 \\
\hline $\mathrm{b}>0$ & 9 & 6 & 8 \\
\hline $\mathrm{b}<0$ & 0 & 3 & 1 \\
\hline \multicolumn{4}{|l|}{ Baseline $(n=8)$} \\
\hline Median plasma concentration, $\%$ & 40.5 & 20 & 75 \\
\hline Standard deviation & 21.3 & 19.8 & 20.6 \\
\hline Out of normal range, $n$ & 5 & 9 & 3 \\
\hline \multicolumn{4}{|l|}{ 1st trimester $(n=2)$} \\
\hline Median plasma concentration, $\%$ & 41.1 & 39.5 & 60.3 \\
\hline \multicolumn{4}{|l|}{ 2nd trimester $(n=5)$} \\
\hline Median plasma concentration, $\%$ & 88.7 & 67.9 & 85 \\
\hline \multicolumn{4}{|l|}{ 3rd trimester $(n=9)$} \\
\hline Median plasma concentration, $\%$ & 91.2 & 21.6 & 98.8 \\
\hline Standard deviation & 49.2 & 44.6 & 43.5 \\
\hline Out of normal range, $n$ & 3 & 5 & 3 \\
\hline \multicolumn{4}{|c|}{ Difference between baseline and 3rd trimester $(n=9)$} \\
\hline Median plasma concentration, $\%$ & 45.2 & 6.3 & 35 \\
\hline Standard deviation & 31.3 & 26.4 & 29.4 \\
\hline
\end{tabular}


Fig. 2. VWF:Ag (green dots, blue line), VWF:RCo (purple squares, red line), and FVIII:C (green triangles, green line) during pregnancy in patients with VWD type 2.

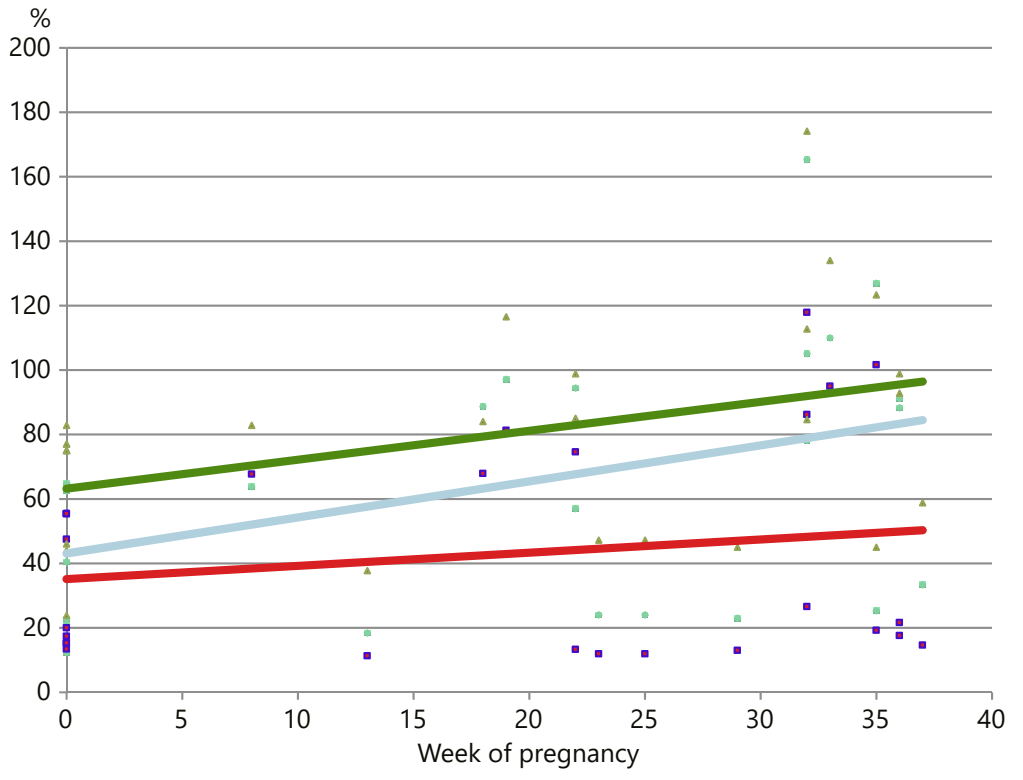

nancy. The median difference between baseline and plasma concentrations in the third trimester of VWF:Ag was $45.2 \%(0.2-102.8 \%, \sigma=31.3)$, that of VWF:RCo was $6.3 \%$ ( -2.8 to $70.4 \%, \sigma=26.4)$, and that of FVIII:C was $35 \%(-1$ to $91.3 \%, \sigma=29.4)$. In patients with VWD type 2 subtype $2 \mathrm{~A}$, no increases were found.

\section{Discussion}

Plasma concentrations of the coagulation parameters VWF:Ag, VWF:RCo, and FVIII:C show a complex variability in healthy people. In healthy women, various changes in the coagulation system occur during pregnancy. An increase of VWF:Ag, VWF:RCo, and FVIII:C during pregnancy in healthy individuals has already been described. The equilibrium shifts to procoagulatory processes, possibly to prevent major blood loss during delivery. Postpartum FVIII:C and VWF activities remain at increased levels for 2 days, and on the third day after delivery VWF activity begins to decline [6].

Numerous studies have assessed changes in the coagulation system and the occurrence of complications during pregnancy, childbirth, and the postpartum period. Nowak-Göttl et al. [7] found significant increases of the coagulation parameters VWF:Ag and FVIII:C in healthy pregnant women during pregnancy, with a peak shortly before birth.

Von Willebrand Parameters during Pregnancy
Ewodo et al. [8] found significant increases in VWF:Ag plasma concentration during pregnancy in healthy women and a significant statistical association between blood group and the VWF change. No statistical correlation was found between maternal age and the VWF change. Interestingly, they observed a statistically significant association between the newborns' Apgar scores and the maternal plasma concentration of VWF, and thus suggested that a correlation between foetal stress and VWF production might exist. Drury-Stewart et al. [9] observed the course of several coagulation parameters (VWF:Ag, VWFpp, FVIII, and ADAMTS13 activity) during pregnancy in healthy subjects and found increases of vWF and FVIII activity, whereas ADAMTS13 activity did not change. Furthermore, they discovered differences in VWF's multimeric structure during and outside of pregnancy, and thus suggested that elevated VWF:Ag and FVIII activity during pregnancy in healthy individuals may result from the prolonged half-life of VWF present as a modified multimer.

A broad variability of coagulation factor plasma concentrations is also known to exist in patients with coagulation disorders. In patients with VWD type 1, age-related increases of VWF:Ag, VWF:RCo, and FVIII:C have been observed, but no reduction of bleeding symptoms occurred. In patients with VWD type 2 the parameters mentioned above do not show increases with age, while bleeding symtpoms occur more often $[10,11]$. In patients 
with mild haemophilia A, characterized by a quantitative deficiency of FVIII, age appears to affect the plasma concentration of several coagulation parameters [12].

A complex variability of the plasma concentration of coagulation parameters can also be expected to occur in patients with VWD. Our study examined the changes in the plasma concentration of the coagulation parameters VWF:Ag, VWF:RCo, and FVIII:C in patients with VWD during pregnancy. Data from patients suffering from VWD types 1 and 2 were analysed separately because of the different underlying pathologic mechanisms (quantitative VWF deficiency in VWD type 1 vs. qualitative alteration of VWF in VWD type 2). Patients with VWD type 3 were not included because they show very low VWF levels. In patients with VWD type 1, significant increases in the coagulation parameters VWF:Ag, VWF:RCo, and FVIII:C were observed. Almost all of these patients achieved a normal plasma concentration of the measured coagulation parameters in the last trimester of pregnancy. The median plasma concentrations of VWF:Ag and FVIII:C reached the normal range as early as the first trimester of pregnancy.

Because VWS type 1 is characterized by a quantitative and not a qualitative deficiency of VWF, the occurrence of bleeding complications may decrease when the deficiency is mitigated by the increased plasma concentration during pregnancy. Patients with VWD type 2 showed significant increases in the plasma concentration of VWF:Ag and FVIII:C, but not of VWF:RCo. Four of these 9 patients had coagulation parameters in the normal range in the third trimester. In patients with type $2 \mathrm{VWD}$, the increase of VWF probably does not reduce the bleeding risk in pregnancy because type 2 is characterized by the synthesis of a dysfunctional VWF.

As mentioned above, Nowak-Göttl et al. [7] found significant increases of the coagulation parameters VWF:Ag and FVIII:C in healthy pregnant women. However, the parameters increased more sharply in this healthy population than in patients with VWD included in our study.

In addition to ours, several studies that evaluated changes in the coagulation system and the occurrence of complications during pregnancy, childbirth, and the postpartum period in patients with VWD have been published. Scholz et al. [13] investigated quantitative changes in the coagulation parameters VWF:Ag, VWF:RCo, and FVIII:C in patients with VWD type 1 during pregnancy. The 10 surveyed patients achieved complete normalization of VWF:Ag and VWF:RCo in the second and third trimesters, respectively. The patients required no factor substitution. In this study, bleeding complications were also assessed, and they occurred to a mild degree in only 2 patients (uterine hematoma).

Shahbazi et al. [14] examined bleeding complications during pregnancy in 28 patients with VWD type 1 (6 patients), type 2 (10 patients), and type 3 (12 patients). Most bleeding complications were observed in the first trimester: $57.1 \%$ of patients experienced mostly mild bleeding in the first trimester. This high number of complications may be related to the selection of patients, as 12 of the 28 examined patients suffered from the most severe form of VWD type 3, which is generally associated with a higher risk of bleeding. The number of bleeding complications appeared to decline during the course of pregnancy.

James and Jamison [15] investigated the incidence of bleeding complications in patients with VWD during pregnancy and childbirth compared to the risk in healthy pregnant women. No increased risk to the child's health in VWD patients was found, but an increased risk of bleeding complications was observed during pregnancy and childbirth compared with healthy subjects. No distinction between the different types of VWD was made.

In another study, the postpartum changes in VWF and FVIII plasma concentrations (VWF:Ag, VWF:RCo, and FVIII:C) were compared between patients with VWD and healthy women. In patients with VWD, the VWF values peaked at $4 \mathrm{~h}$ postpartum (median $250 \%$ of baseline), whereas they peaked after $12 \mathrm{~h}$ in healthy mothers. Both groups' VWF levels reached the baseline level after 3 weeks. In some patients with VWD, replacement therapy during the course of labour was necessary. Despite this therapy, coagulation parameters did not reach values similar to those of healthy women giving birth. James et al. [16] concluded that women with VWD are at increased risk of postpartum bleeding, even if they receive treatment. In this study, a distinction was made between different types and subtypes of VWD; all patients with VWD type 2 and $70 \%$ of patients with type 1 needed treatment prior to childbirth (VWF concentrate or desmopressin), and this treatment was performed prophylactically except in 1 case. Ramsahoye et al. [17] described pregnancies in women with VWD type 2 in which early postpartum haemorrhage occurred, although the FVIII:C level in the third trimester was higher than $90 \mathrm{IU} / \mathrm{dL}$. In this study, postpartum haemorrhage occurred in 33\% of the pregnancies in women with VWD type 2. Pregnancy and childbirth proceeded without complication after treatment.

The 2013 Committee Opinion on VWD of the American College of Obstetricians and Gynaecologists [18] recommends close monitoring of changes of VWF and
76

Acta Haematol 2019;142:71-78 DOI: $10.1159 / 000496820$
Delbrück/Miesbach 
FVIII during pregnancy, including the third trimester. Co-operation with a haematologist should be established early to enable a complication-free childbirth and postpartum period. FVIII:C is the best predictor of bleeding complications in pregnancies of women with VWD type 1 , as patients are expected to be at minimal risk of bleeding complications when FVIII:C is in the normal range $(>60 \%)$ at childbirth or at least $>30 \%$. A greater risk is described if the FVIII activity is lower than 30\% [19, 20].

Castaman [21] recommends not to perform any prophylaxis before childbirth in patients with VWD with baseline parameters of FVIII:C and VWF activity $>30 \mathrm{U} /$ dL. Patients with baseline parameters below $20 \mathrm{U} / \mathrm{dL}$ should be treated with desmopressin (in the case of underlying mutation with clearance change in VWF) or factor substitution (in compound heterozygosity). Substitution treatment should be maintained for several days postpartum to prevent late bleeding. If necessary, tranexamic acid should be given to prevent excessive lochia.

The limitation of our study is that it was conducted retrospectively and only patients from one specialised centre were included. As a consequence, the results of our study are of limited transferability. Unfortunately, no data on complications during childbirth, postpartum changes in coagulation parameters, or postpartum bleeding symptoms were recorded. Furthermore, no blood group adjustment could be done, since the data were not available.

\section{Conclusion}

Our study showed that coagulation parameters rise during pregnancy. Measured parameters normalized in all patients with VWD type 1 and in 4 of 9 patients with VWD type 2. Despite these results patients with VWD should undergo close monitoring of coagulation parameters and bleeding symptoms during pregnancy, childbirth, and the postpartum period to prevent abortion and other complications. Because of the risk of infection, allergic reaction, and other associated effects on pregnancy, the choice for factor substitution or prophylaxis should be made only under strict indications. Prospective studies are needed to investigate the course of haemostasis parameters, bleeding symptoms, and complications during pregnancy and the intra- and postpartum periods in patients with VWD type 1,2, and 3 to assess and minimize risk and establish effective treatments.

\section{Statement of Ethics}

The Ethics Commission of the University Hospital Frankfurt am Main, Germany, approved this study.

\section{Disclosure Statement}

The authors do not have any conflicts of interest.

\section{References}

1 De Meyer SF, Deckmyn H, Vanhoorelbeke K. von Willebrand factor to the rescue. Blood. 2009 May; 113(21):5049-57.

2 Castaman G, Goodeve A, Eikenboom J; European Group on von Willebrand Disease. Principles of care for the diagnosis and treatment of von Willebrand disease. Haematologica. 2013 May;98(5):667-74.

3 James AH. More than menorrhagia: a review of the obstetric and gynaecological manifestations of von Willebrand disease. Thromb Res. 2007;120 Suppl 1:S17-20.

4 Hellgren M. Hemostasis during normal pregnancy and puerperium. Semin Thromb Hemost. 2003 Apr;29(2):125-30.

5 Rodeghiero F, Tosetto A, Abshire T, Arnold DM, Coller B, James P, et al.; ISTH/SSC joint VWF and Perinatal/Pediatric Hemostasis Subcommittees Working Group. ISTH/SSC bleeding assessment tool: a standardized questionnaire and a proposal for a new bleeding score for inherited bleeding disorders. J Thromb Haemost. 2010 Sep;8(9): 2063-5.
6 Huq FY, Kulkarni A, Agbim EC, Riddell A, Tuddenham E, Kadir RA. Changes in the levels of factor VIII and von Willebrand factor in the puerperium. Haemophilia. 2012;18(2): 241-5.

7 Nowak-Göttl U, Limperger V, Kenet G, Degenhardt F, Arlt R, Domschikowski J, et al. Developmental hemostasis: a lifespan from neonates and pregnancy to the young and elderly adult in a European white population. Blood Cells Mol Dis. 2017 Sep;67:2-13.

8 Ewodo S, Nguefack CT, Adiogo D, Etong EM, Beyiha G, Belley PE. [Changes of Von Willebrand factor concentration during pregnancy]. Ann Biol Clin (Paris). 2014 May-Jun; 72(3):292-6.

9 Drury-Stewart DN, Lannert KW, Chung DW, Teramura GT, Zimring JC, Konkle BA, et al. Complex changes in von Willebrand factorassociated parameters are acquired during uncomplicated pregnancy. PLoS One. 2014 Nov;9(11):e112935.

10 Rydz N, Grabell J, Lillicrap D, James PD. Changes in von Willebrand factor level and von Willebrand activity with age in type 1 von Willebrand disease. Haemophilia. 2015 Sep; 21(5):636-41.

11 Sanders YV, Giezenaar MA, Laros-van Gorkom BA, Meijer K, van der Bom JG, Cnossen $\mathrm{MH}$, et al.; WiN study group. von Willebrand disease and aging: an evolving phenotype. J Thromb Haemost. 2014 Jul; 12(7):1066-75.

12 Delbrück C, Haferland I, Scholz K, Asmelash G, Makki V, Müller S, et al. [Does FVIII-activity increase with age in patients with haemophilia A and carriers of haemophilia A?]. Hamostaseologie. 2011 Nov;31 Suppl 1:S248.

13 Scholz U, Oppermann J, Siegemund A, Schobess R. [Von Willebrand disease type 1 and pregnancy]. Hamostaseologie. 2011 Nov; 31 Suppl 1:S11-3.

14 Shahbazi S, Moghaddam-Banaem L, Ekhtesari F, Ala FA. Impact of inherited bleeding disorders on pregnancy and postpartum hemorrhage. Blood Coagul Fibrinolysis. 2012;23(7): 603-7. 
15 James AH, Jamison MG. Bleeding events and other complications during pregnancy and childbirth in women with von Willebrand disease. J Thromb Haemost. 2007 Jun;5(6): $1165-9$.

16 James AH, Konkle BA, Kouides P, Ragni MV, Thames B, Gupta S, et al. Postpartum von Willebrand factor levels in women with and without von Willebrand disease and implications for prophylaxis. Haemophilia. 2015; 21(1):81-7.
17 Ramsahoye BH, Davies SV, Dasani H, Pearson JF. Obstetric management in von Willebrand's disease: a report of 24 pregnancies and a review of the literature. Haemophilia. 1995;1:140-4.

18 Committee on Adolescent Health Care; Committee on Gynecologic Practice. Von Willebrand's disease in women. Committee Opinion No. 580. Obstet Gynecol. 2013 Dec; 122(6): 1368-73.

19 Castaman G, Tosetto A, Rodeghiero F. Pregnancy and delivery in women with von Will- ebrand's disease and different von Willebrand factor mutations. Haematologica. 2010 Jun; 95(6):963-9.

20 Mannucci PM. Treatment of von Willebrand's Disease. N Engl J Med. 2004 Aug; 351(7):683-94

21 Castaman G. Changes of von Willebrand Factor during Pregnancy in Women with and without von Willebrand Disease. Mediterr J Hematol Infect Dis. 2013 Jul;5(1): e2013052. 